\title{
Bronchial Artery Embolization Performed in COVID-19 Patients: Tolerance and Outcomes
}

\author{
Matthias Barral $^{1}$ (D) Marc Sirol $^{2} \cdot$ Mostafa El Hajjam $^{2} \cdot$ Norbert Zhang $^{2} \cdot$ \\ Arthur Petit ${ }^{3} \cdot$ François H. Cornelis ${ }^{1}$
}

Received: 4 May 2020/Accepted: 5 August 2020/Published online: 26 August 2020

(C) Springer Science+Business Media, LLC, part of Springer Nature and the Cardiovascular and Interventional Radiological Society of Europe (CIRSE) 2020

Dear Editor,

From the 23rd of February 2020, corresponding to the beginning of stage 1 epidemic outbreak in France, to the 5th of May, 25 patients (men: 24/25; 96\%) with a mean age of $57 \pm 17$ years [16-84] had bronchial artery embolization (BAE) for severe hemoptysis (SH). All BAE was performed in a decontaminated positive pressure angiography suite. COVID-19 patients followed a specific pathway including a dedicated intensive care unit (ICU) and elevator. In addition, staff had personal protective equipment including a FFP2 mask, gown, goggles and shoe protection and a face shield [1].

A total of 4 men with 7 BAE had positive COVID-19 RT-PCR (Tables 1, 2), and 3 patients had severe acute

Matthias Barral

matthiasbarral@gmail.com

Marc Sirol

marc.sirol@aphp.fr

Mostafa El Hajjam

mostafa.elhajjam@aphp.fr

Norbert Zhang

norbert.zhang@aphp.fr

Arthur Petit

arthur.petit@aphp.fr

François H. Cornelis

francois.cornelis@aphp.fr

1 Interventional and Oncological Radiology, Hopital Tenon, Assistance Publique des hôpitaux de Paris, Paris, France

2 Radiology, Hopital Ambroise Paré, Assistance Publique des Hôpitaux de Paris, Boulogne-Billancourt, France

3 Radiology, Hopital Avicenne, Assistance Publique des Hôpitaux de Paris, Bobigny, France respiratory syndrome (SARS-CoV-2). Subpleural and inferior bilateral ground-glass opacities with crazy-paving suggesting COVID-19 were found in 3 patients with $<50 \%$ of pulmonary involvement in one patient and $>75 \%$ in 2 patients. Bronchial arteries enlargement was seen in 3 patients, and 3 patients had consolidation; no patient had alveolar hemorrhage compared to $17(17 / 21$; $81 \%$ ) non-COVID-19 patients $(p=0.005$, Chi-square test) (Fig. 1). Of all, $71 \%$ of BAE was performed under general anesthesia for COVID-19 patients, and none in the nonCOVID-19 group $(p<0.01$, Chi-square test). Microspheres were the most common embolization material, $87 \%$ and $71 \%$ respectively. Pulmonary shunt was more frequent in COVID-19 (71\% vs. $17 \%, p<0.01$, Chisquare test) (Fig. 2).

Embolization of all eutopic and heterotopic bronchial arteries was performed in $86 \%$ of COVID-19 patients during the first BAE, and 24-h clinical efficacy was 75\% and $100 \%$ after a second BAE. Thirty-day mortality was $10 \%(2 / 21)$ in the non-COVID-19 group and $0 \%$ in the COVID-19 group. No complication related to BAE was reported. The mean ICU length of stay was superior in COVID-19 patients $23 \pm 8$ days [13-32] versus $12 \pm 14$ days [1-46] ( $p=0.007$, Student $t$ test).

This case series is the first describing clinical, imaging and outcome of SH and COVID-19 treated with BAE. One patient had bronchiectasis and COVID-19; conversely, the 3 others with SARS-COV-2 had no bronchial or pulmonary condition favoring SH, suggesting the role of COVID-19 in pulmonary parenchyma injury responsible for $\mathrm{SH}$. Of note, all SARS-COV-2 patients had heparin for deep venous thrombosis prophylaxis favoring $\mathrm{SH}$. 
Table 1 Patients characteristics

\begin{tabular}{|c|c|}
\hline & $\begin{array}{l}\text { COVID } 19 \\
(n=4)\end{array}$ \\
\hline Age & $55 \pm 6[47-63]$ \\
\hline Men & $4(4 / 4 ; 100 \%)$ \\
\hline BMI $\left(\mathrm{kg} \mathrm{m}^{2}\right)$ & $25.18 \pm 5.6[19-31]$ \\
\hline Diabetes & $2(2 / 4 ; 50 \%)$ \\
\hline Hypertension & $3(3 / 4 ; 75 \%)$ \\
\hline Smoking habit & - \\
\hline Hemoptysis quantity & $250 \pm 41[200-300]$ \\
\hline Optic fibroscopy & $4(4 / 4 ; 100 \%)$ \\
\hline \multicolumn{2}{|l|}{ Etiology of hemoptysis } \\
\hline Idiopathic & - \\
\hline Infection & $3(3 / 4 ; 75 \%)$ \\
\hline Bronchiectasis & $1(1 / 4 ; 25 \%)$ \\
\hline Cancer & - \\
\hline Tuberculosis & - \\
\hline Other & - \\
\hline Days since the beginning of COVID-19 symptoms & $21 \pm 15[2-34]$ \\
\hline Days since the beginning of stage 1 pandemic & $40 \pm 16[18-53]$ \\
\hline Enhanced CT & $4(4 / 4 ; 100 \%)$ \\
\hline Alveolar hemorrhage & - \\
\hline Condensation & $3(3 / 4 ; 75 \%)$ \\
\hline Dilated bronchial arteries & $3(3 / 4 ; 75 \%)$ \\
\hline Pulmonary artery lesion & - \\
\hline COVID-19 imaging features & $3(3 / 4 ; 75 \%)$ \\
\hline \multicolumn{2}{|l|}{ Extent of COVID-19 imaging features } \\
\hline$<10 \%$ & - \\
\hline $10-25 \%$ & - \\
\hline $25-50 \%$ & $1(1 / 4 ; 25 \%)$ \\
\hline $50-75 \%$ & $1(1 / 4 ; 25 \%)$ \\
\hline$>75 \%$ & $1(1 / 4 ; 25 \%)$ \\
\hline
\end{tabular}

Table 2 Results of embolization

\begin{tabular}{ll}
\hline & $\begin{array}{l}\text { COVID-19 } \\
(n=7)\end{array}$ \\
\hline $\begin{array}{l}\text { General anesthesia } \\
\text { Number of bronchial arteries embolized }\end{array}$ & $5(5 / 7 ; 71 \%)$ \\
Type of embolic material & $2.5 \pm 0.6[2-3]$ \\
Microspheres & $5(5 / 7 ; 71 \%)$ \\
Coils & $1(1 / 7 ; 14 \%)$ \\
Onyx & $1(1 / 7 ; 14 \%)$ \\
Immediate technical success & $6(6 / 7 ; 86 \%)$ \\
Pulmonary shunt & $5(5 / 7 ; 71 \%)$ \\
Bronchial-medullary anastomoses & - \\
Dilated bronchial arteries & $6(6 / 7 ; 86 \%)$ \\
Pulmonary artery lesion & - \\
\hline
\end{tabular}

Characteristics of BAE were similar between groups suggesting the absence of influence of COVID-19 on the catheter or embolic material choice. COVID-19 patients did not demonstrate localized alveolar hemorrhage on CT. However, COVID-19 imaging features and alveolar hemorrhage overlap and may lead to misinterpretation. Consequently, the performance of chest CT to identify and localize the bleeding site may be hampered [2]. Localization of hemoptysis should, thus, solely be based on the results of fibroscopy.

At angiography, COVID-19 patients demonstrated more frequently pulmonary shunts. This may be the result of distal microembolisms in pulmonary arteries [3]. The pulmonary alveolus vascular supply may then be supported by bronchial arteries, favoring an antegrade bronchialpulmonary shunt [4].

Thanks to a dedicated COVID-19 pathway and strong safety guidelines, no chances were lost for COVID-19 and non-COVID-19 patients, making possible the practice of 


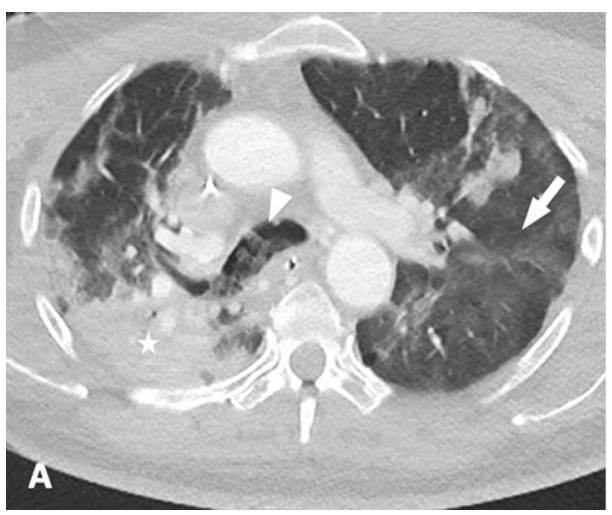

Fig. 1 Contrast-enhanced chest computed tomography at the arterial phase in a 63-year-old patient with severe acute respiratory syndrome due to coronavirus 2019. A Chest CT demonstrates goggle-glass opacities with crazy-paving (white arrow), posterior condensation in

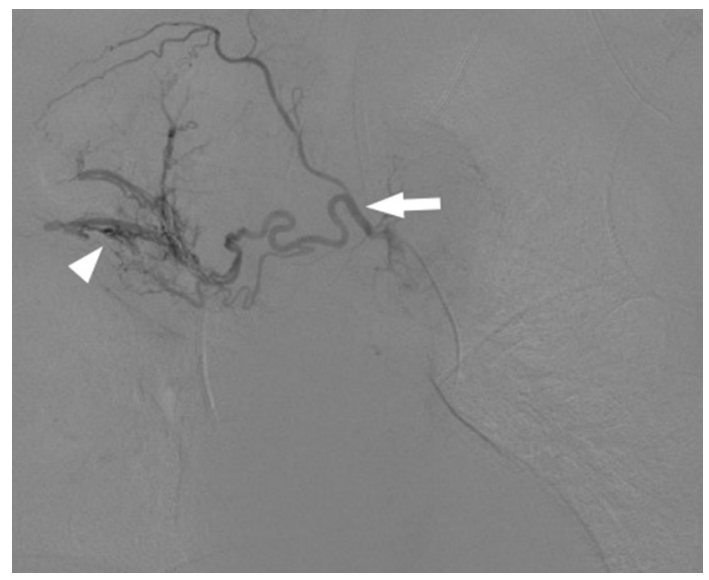

Fig. 2 Digital subtractive angiography of right intercostobronchial artery. Selective catheterization demonstrates dilated bronchial artery with antegrade filling of the right upper lobe pulmonary artery, consistent with a bronchial-pulmonary arterial shunt

emergency interventional radiology (IR). In our study, COVID-19 infection status in the first positive patient was unknown and safety guidelines were neglected. He was possibly responsible for the contamination of two members of the IR staff. Of interest, the conversion of positive to negative pressure room during infectious airborne disease outbreak should be considered to limit the pathogen dispersion to personnel working in adjacent areas [5].

Management of SH in COVID-19 patients with BAE was feasible and efficient. However, respect of safety guidelines is of utmost importance to protect the IR staff.

Funding This study was not supported by any funding.

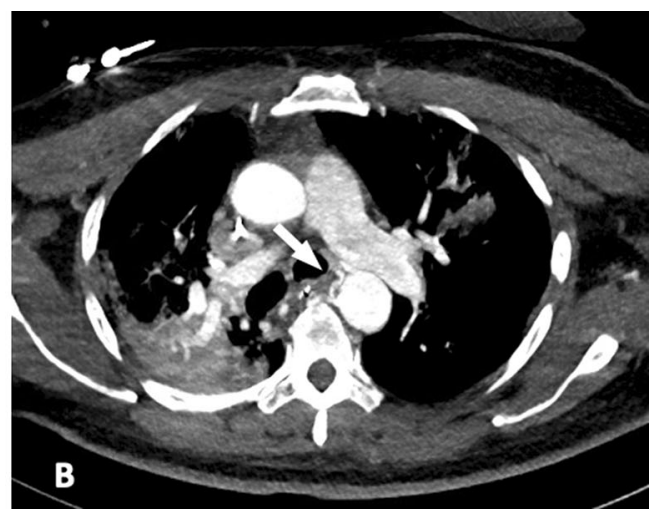

the right upper lobe (white star) and a filling of the proximal right bronchus with hemorrhagic material (white arrowhead). B Chest CT demonstrates dilated bronchial arteries related to bronchial hypervascularization

\section{Compliance with Ethical Standards}

Conflict of interest The authors declare that they have no conflict of interest.

Ethical Approval All procedures performed in studies involving human participants were in accordance with the ethical standards of the institutional and/or national research committee and with the 1964 Helsinki Declaration and its later amendments or comparable ethical standards.

Informed Consent For this type of study, formal consent is not required. Informed consent was obtained from all individual participants included in the study.

Consent for Publication Consent for publication was obtained for every individual person's data included in the study.

\section{References}

1. Ierardi AM, Wood BJ, Gaudino C, Angileri SA, Jones EC, Hausegger K, et al. How to handle a COVID-19 patient in the angiographic suite. Cardiovasc Intervent Radiol. 2020;43(6):820-6.

2. Revel MP, Fournier LS, Hennebicque AS, Cuenod CA, Meyer G, Reynaud P, et al. Can CT replace bronchoscopy in the detection of the site and cause of bleeding in patients with large or massive hemoptysis? AJR Am J Roentgenol. 2002;179(5):1217-24.

3. Grillet F, Behr J, Calame P, Aubry S, Delabrousse E. Acute pulmonary embolism associated with COVID-19 pneumonia detected by pulmonary CT angiography. Radiology. 2020;296(3):186-8.

4. Khalil A, Fedida B, Parrot A, Haddad S, Fartoukh M, Carette M-F. Severe hemoptysis: from diagnosis to embolization. Diagn Intervent Imaging. 2015;96(7-8):775-88.

5. Chow TT, Kwan A, Lin Z, Bai W. Conversion of operating theatre from positive to negative pressure environment. J Hosp Infect. 2006;64(4):371-8.

Publisher's Note Springer Nature remains neutral with regard to jurisdictional claims in published maps and institutional affiliations. 